\title{
La configuración turística de las periferias urbano-rurales mediante estrategias gubernamentales. El caso de Xochimilco, Ciudad de México ${ }^{1}$
}

\section{The tourist configuration of urban-rural peripheries through government strategies. The case of Xochimilco, Mexico City}

Alejandra Pérez Galicia, Universidad Nacional Autónoma de México, México.

ale.perez.galicia@gmail.com

Enrique Pérez Campuzano, Universidad Nacional Autónoma de México, México. eperez@igg.unam.mx

Genaro Javier Delgado Campos, Universidad Nacional Autónoma de México, México.

interfase7@gmail.com

\section{RESUMEN}

La implementación de actividades turísticas en la periferia de la Ciudad de México es un fenómeno que se ha presentado desde hace más de un siglo. No obstante, la dinámica de estas actividades se ha modificado por las necesidades sociales sobre el espacio y por los efectos de la expansión urbana. Se parte del análisis de la territorialidad turística y sus efectos urbanizadores, fenómenos que son visibles en la periferia urbano-rural de la Ciudad de México, especialmente en la alcaldía de Xochimilco, espacio que atraviesa por conflictos urbanos, económicos, sociales y ambientales como consecuencia de este fenómeno. Este artículo presenta una revisión histórica de las estrategias gubernamentales que han impulsado el turismo en Xochimilco, se concluye con una reflexión sobre el futuro de las periferias urbanas.

Palabras Clave: Turismo Periférico, territorialidad turística, Xochimilco.

\section{ABSTRACT}

The implementation of activities in the outskirts of Mexico City is a phenomenon that has been taking place for more than a century. However, the dynamics of these activities have been modified by the social needs of space and by the effects of urban expansion. The study

1. Este artículo forma parte de la tesis "El turismo periférico en el Suelo de Conservación de Xochimilco. Del turismo de desarrollo al turismo de conservación" presentada para obtener el Doctorado en Diseño y Estudios Urbanos en la Universidad Autónoma Metropolitana Unidad Azcapotzalco.

El proyecto se realizó en el marco del proyecto de Ciencia Básica CONACYT 179301 Valoración Económica del Suelo de Conservación del Instituto de Geografía de la UNAM. 
is based on the analysis of tourism territoriality and its urbanizing effects, phenomena that are visible in the urban-rural periphery of Mexico City, especially in the municipality of Xochimilco, which is experiencing urban, economic, social and environmental conflicts as a result of this phenomenon. This paper presents a historical review of the strategies that have driven tourism in Xochimilco, it concludes with a reflection on the future of the urban peripheries.

Keywords: Peripheral tourism, Territoriality of tourism; Xochimilco.

\section{ANTECEDENTES}

El turismo periurbano se basa no sólo en los recursos ambientales, sino también sociales y culturales, particularmente en las tradiciones rurales locales, la historia, geografía y patrimonio (Yang, Cai, \& Sliuzas, 2010). Con ello puede promover más de un segmento turístico en las periferias, además de aprovechar las condiciones geográficas y de conectividad con las ciudades (Chaperon \& Bramwell, 2013).

No obstante, las periferias, como la que presentamos en este artículo, enfrentan numerosos problemas para integrarse a la actividad turística: la falta de infraestructura, los imaginarios turísticos formados en torno al destino, el tejido social de grupos originarios vulnerables ante la llegada del turismo, el manejo inadecuado de residuos sólidos (Nash \& Martin, 2003) y la competencia por el uso de espacios y recursos.

Son diversos los autores que consideran a las periferias como espacios de difícil acceso o bien distantes a los centros urbanos que generan turistas (Nash \& Martin, 2003), pero en el caso de estudio esto no es así. Xochimilco, junto con Tláhuac; representan a las alcaldías de la Ciudad de México que aún cuentan con parte de los canales históricos que recorrían la

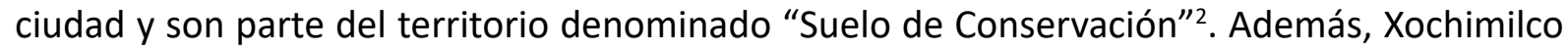
se comunica con el centro de la Ciudad de México mediante vialidades y sistemas de transporte colectivo, por lo que se constituye como una centralidad.

También se menciona que el turismo periférico es propio de espacios donde la agricultura tradicional ya no es relevante (Nash \& Martin, 2003; Zasada, 2011). Esto no se cumple del todo en la periferia de la Ciudad de México en general y en Xochimilco en particular. Esta alcaldía es la zona agrícola más tradicional del Valle de México, además de contar con los nombramientos de Patrimonio de la Humanidad por la Organización de las Naciones Unidas para la Educación, la Ciencia y la Cultura (UNESCO) y como Sistema Importante del Patrimonio Agrícola Mundial de la Organización de las Naciones Unidas para la Alimentación y la Agricultura (FAO) sobre el cultivo en chinampas ${ }^{3}$. Sin embargo, dichos espacios se encuentran en riesgo ante el

2. "El suelo de conservación se refiere a las zonas que, por sus características ecológicas, proveen servicios ambientales, necesarios para el mantenimiento de la calidad de vida de los habitantes de la Ciudad de México, de conformidad con lo establecido en la Ley Ambiental del Distrito Federal" (PAOT, 2007).

3. Del náhuatl chinampan: "en la cerca de cañas", la chinampa es un sistema artificial de cultivo que se construye en zonas donde los cuerpos de agua ocupan la mayor parte de la superficie. En estos espacios se cultivan plantas, verduras y hortalizas para el autoconsumo y mercado local.

Si bien se cree que esta técnica inició en la época de los toltecas, fue hasta 1519 que este método de cultivo se popularizó y ocupó casi el 100 por ciento del lago Xochimilco, permitiendo el desarrollo de una de las poblaciones más importantes en el valle de México (SAGARPA, 2018). 
avance de la expansión urbana y el cambio de uso de suelo agrícola tradicional a invernaderos o de servicios turísticos.

Xochimilco ofrece, desde principios del siglo XX, una amplia gama de actividades recreativas: recorridos por canales, contacto con la naturaleza en sus parques ecológicos 0 bosques urbanos, tradiciones como la festividad del día de muertos, las fiestas religiosas como la del Niño Pa (que pueden durar varias semanas), además del certamen de belleza local "La Flor más Bella del Ejido" y las ventas de productos de la región por temporadas. La periferia de Xochimilco no depende de una modalidad turística única, cuestión que sucede en otros destinos, como es el caso de Australia (Hohl \& Tisdell, 1995).

Por tanto, establecemos que, a pesar de que la relación turismo-periferia es larga, los estudios sobre el turismo y su impacto urbanizador en estos espacios es escasa (Pérez, 2018), lo cual lleva a que el turismo participe en la generación de impactos negativos a nivel ecológico (cambio de uso de suelo y contaminación), económico (distribución desigual de recursos) y sociales (inequidad social). No obstante, hay impactos positivos como la generación de empleo, la mejora de la calidad de vida de los habitantes y la disminución de la migración (Pérez, 2018), mismos que serían mayores si el turismo se implementara de una forma menos desarticulada entre agencias de gobierno, pobladores e inversionistas.

En este artículo desplegamos la evolución de la espacialidad del turismo periférico en Xochimilco, uno de los destinos obligatorios para visitantes locales, nacionales y extranjeros. El sitio cuenta con una serie de atributos naturales y culturales que han sido explotados por el turismo mediante estrategias gubernamentales implementadas como una vía de desarrollo y conservación, mas no se han considerado sus efectos de transformación espacial, mismos que se han integrado a la cotidianeidad de la zona y pasan desapercibidos.

Tales transformaciones son resultado de una dinámica territorial, abordada en el primer apartado del artículo, donde el turismo ha influido en la definición del uso de suelo de Xochimilco desde hace más de un siglo en combinación con las necesidades de espacio de sus habitantes, visitantes y turistas.

Este artículo es resultado de una investigación basada en el triple efecto de la historia, la periurbanización y el turismo periférico, una revisión bibliohemerográfica sobre la actividad turística en Xochimilco y las modificaciones urbanas generadas ${ }^{4}$, una búsqueda y revisión de los decretos, leyes y programas publicados en materia de patrimonio cultural, medio ambiente, turismo y desarrollo urbano de Xochimilco. Información con la cual fue posible hacer una reflexión sobre la espacialidad del turismo entre 1900 y 2016. De igual modo, se integran algunas reflexiones sobre vivir y trabajar en un espacio turístico obtenidas de entrevistas a profundidad en las que participaron agricultores, prestadores de servicios turísticos, habitantes y representantes de pueblos y barrios de Xochimilco.

4. Se consultaron: el acervo de la Hemeroteca Nacional de México (notas sobre actividades recreativas, excursiones, apertura de comercios, clubes y la construcción del acueducto), la colección sobre Xochimilco publicada por el Instituto de Investigaciones Dr. José María Luis Mora, textos del Instituto Nacional de Antropología e Historia, el Consejo Nacional para la Cultura y las Artes y artículos especializados. 
Finalmente, se presentan una serie de cavilaciones sobre el futuro de Xochimilco como periferia turística, así como algunas propuestas para una implementación más sustentable del turismo en estos espacios.

\section{TERRITORIALIDAD DEL TURISMO Y URBANIZACIÓN}

El territorio, se puede construir y reconstruir conforme a las necesidades de uso y apropiación social del espacio (Diniz \& Moquete, 2011), entre las cuales se encuentra el turismo. Por tanto, es necesario abordar esta integración desde un enfoque territorial, donde el turismo ha modificado y reordenado el territorio mismo (da Silva \& Correia, 2015; Gómez, 2005; Hiernaux, 1989).

Hablamos de espacios construidos y reconstruidos continuamente como consecuencia de la demanda creciente de lugares recreativos, tanto por visitantes como por habitantes, lo que ha llevado a la diversificación de la oferta. En el caso de las grandes ciudades esta diversificación es un reto, especialmente por la falta de espacio, por ello las periferias cercanas se ven como un escenario ideal. Además, las periferias significan una oportunidad para crear espacios turísticos únicos, gracias a la presencia de escenarios naturales, vestigios históricos y comunidades tradicionales.

Por otro lado, uno de los objetivos incorporados al discurso de los beneficios turísticos es el de sustentabilidad, donde el turismo en las comunidades receptoras genera nuevos empleos, promueve la conservación de áreas con valor ambiental y de las actividades tradicionales, usos y costumbres. Sin embargo, al formar parte de una tendencia global, el turismo se vuelve un conector local-global que entabla la interacción entre diversas culturas, contribuyendo a procesos de hibridación, asimilación y traducción cultural (Diniz y Moquete, 2011).

Sobre la posibilidad de generar nuevos empleos, abrir actividades económicas distintas a las tradicionales y conservar las costumbres, es importante señalar que las periferias urbano-rurales se distinguen por el trabajo agropecuario, especialmente de agricultura, la que contribuye a la conservación del paisaje y de los escenarios naturales, ideales para desarrollar prácticas recreativas, educativas y culturales. Esta posibilidad donde el turismo y la agricultura se llevan a cabo en un mismo espacio se conoce como agricultura periférica multifuncional (Zasada, 2011), donde se debe mantener un equilibrio entre la competencia económica que generan ambas actividades y el probable desplazamiento de la agricultura por el turismo, manteniendo la vocación tradicional de los espacios.

La promoción de la actividad turística, los cambios de uso de suelo y el desplazamiento de las actividades económicas tradicionales, estimulan una cierta reinterpretación de la memoria y de tradiciones en el territorio que a su vez implican un cambio cultural para atender las necesidades de la nueva demanda y deja de lado las costumbres locales (Diniz y Moquete, 2011). Esta afectación se debe, en gran medida, a la deficiente planeación urbana que estimula fenómenos como: el consumo acelerado de recursos, el incremento de la presión sobre los campesinos para que produzcan más alimentos (Allen, 2003), el cambio de uso de suelo y la generación de residuos sólidos urbanos (para los que no está preparada la comunidad originaria (Arias \& Ávila, 2013)), y la reducción de las áreas de cultivo, lo que obliga a traer 
productos agrícolas de otras regiones cercanas que, poco a poco, se convertirán en nuevas periferias todavía más alejadas (Allen, 2003).

En suma, el turismo periférico, no necesariamente contribuye a preservar la agricultura, sino que compite con ella por los espacios mejor localizados. En la Ciudad de México es posible encontrar antiguas zonas de cultivo destinadas actualmente a campos de fútbol, cabañas, áreas de comida, circuitos para ciclistas y corredores, entre otros. Esta conversión forzosa se debe a una conceptualización muy débil sobre el papel del turismo periférico en la conservación de las actividades primarias, el crecimiento y decrecimiento urbano, el detrimento ambiental, la conservación y la mercantilización de la cultura.

\section{XOCHIMILCO, REMANENTE LACUSTRE DE ALTO VALOR AMBIENTAL Y CULTURAL}

Xochimilco, alcaldía ubicada al sureste de la Zona Metropolitana de la Ciudad de México (ver mapa 1). Destaca por su importante cobertura vegetal ( $80 \%$ de su territorio), denominada como Suelo de Conservación, de este espacio, 15\% pertenece a la Categoría de Área Natural Protegida ${ }^{5}$. En términos ambientales, Xochimilco es una de las zonas más valiosas de la Ciudad de México, ya que posee una zona lacustre donde todavía existen $184 \mathrm{~km}$ de canales del lago original.

Mapa 1. Ubicación de la zona de estudio

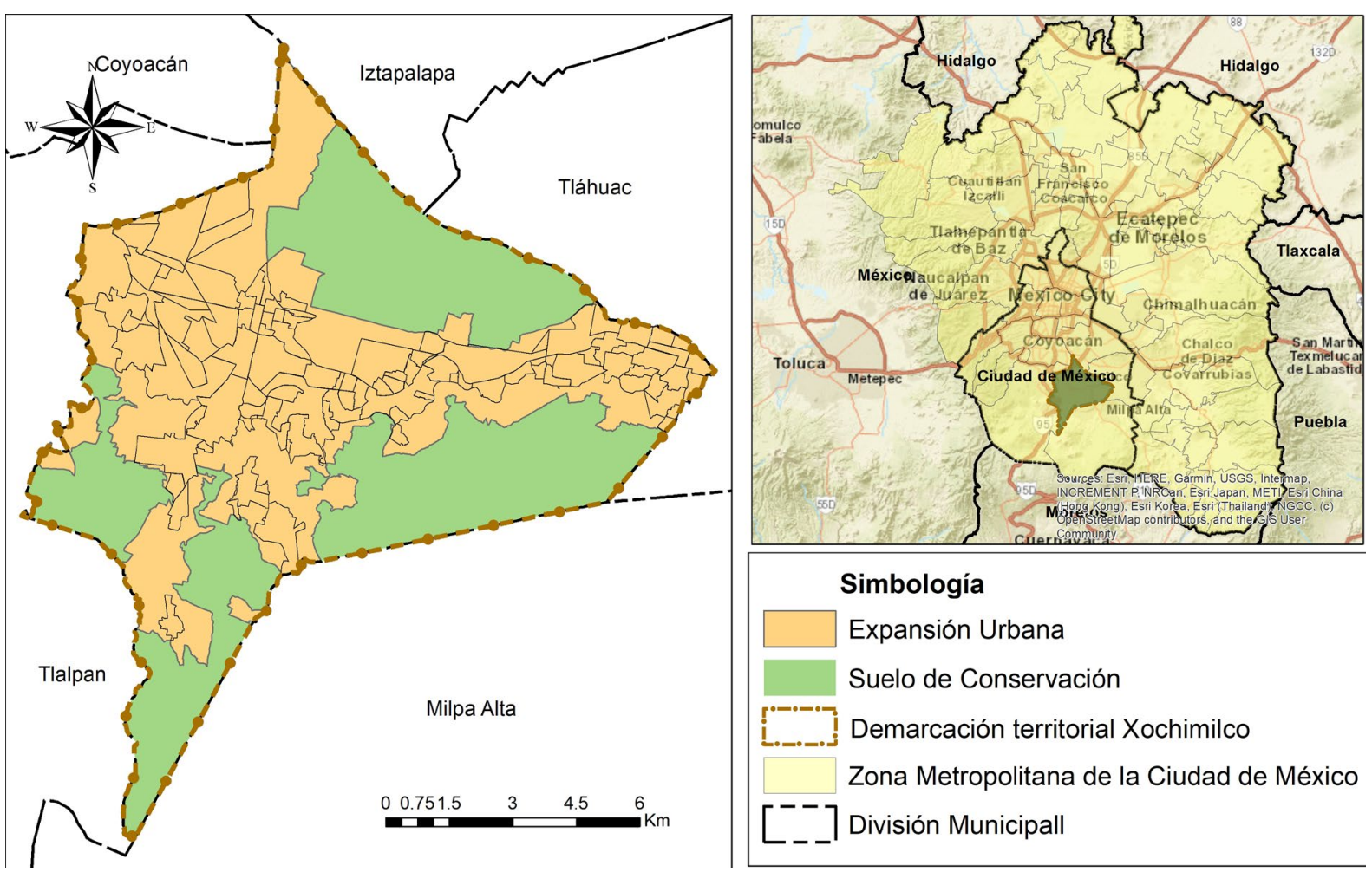

Fuente: Elaboración propia con base en Instituto Nacional de Estadística y Geografía (INEGI).

5. Áreas naturales protegidas: "Zonas del territorio nacional donde los ambientes originales no han sido significativamente alterados por la actividad del ser humano o que requieren ser preservadas y restauradas y están sujetas al régimen previsto en la ley" (LGEEPA, 1988) 
Cuenta, además, con el decreto nacional de Zona de Monumentos Históricos, el internacional de Patrimonio Mundial de la Humanidad de la UNESCO, sitio de conservación RAMSAR y el reconocimiento de las chinampas como Sistema Importante del Patrimonio Agrícola Mundial (SIPAM) por parte de la FAO. Cuestiones que, sumadas a la riqueza natural y cultural, convierten a Xochimilco en unos de los destinos más visitados en la Ciudad de México.

A pesar de esos decretos, la expansión urbana de la megalópolis ha traído como consecuencia una presión por cambio de uso de suelo que parece no detenerse. Esto se debe a que aún funciona como una centralidad antigua para la región y conjunta la mayor parte de servicios de transporte, servicios públicos y privados.

Si bien esta expansión se dio a partir de los años 50, es importante señalar que Xochimilco existe desde la época prehispánica y que ha enfrentado diversos cambios en su territorio a partir de la conquista. No obstante, siempre ha mantenido su característica producción en chinampa y, contra la creencia general, se convirtió en un destino turístico a principios del siglo XX como parte de una estrategia gubernamental para promover una imagen folklórica de la Ciudad de México.

\subsection{Génesis del turismo en Xochimilco, 1900-1914}

Hacia finales del siglo XIX y principios del XX, durante parte del periodo porfirista, México experimentó un proceso de intensa modernización tendiente a imitar los modelos de desarrollo europeos, entre ellos: la oferta de actividades recreativas en escenarios naturales. Fue en medio de esta dinámica que el turismo comenzó a promoverse en diferentes regiones del país, incluyendo a Xochimilco.

Desde 1891 ya se percibía una cierta actividad turística en Xochimilco. El poblado y su lago eran visitados por políticos, artistas y extranjeros (Hernández, 2003), quienes encontraban una zona recreativa y de descanso, relativamente cerca de la ciudad. De este modo, se puede hablar del inicio de una periferia turística similar a la expuesta por Hiernaux $(2008)^{6}$.

El último remanente lacustre se constataba como un territorio natural privilegiado, donde se ofrecían "fiestas campestres" para celebraciones nacionales e internacionales. Un ejemplo notable fue la fiesta que el gobierno ofreció para los delegados de la Segunda Conferencia Panamericana en los canales de Nativitas en diciembre de 1901. Durante dicha fiesta, se realizaron recorridos en canoas y embarcaciones de vapor, en los que fue posible admirar un jardín submarino diseñado por los habitantes locales, quienes tejieron tule con flores y posteriormente lo sumergieron en el fondo del lago (Hernández, 2003). En esta ocasión también se visitaron algunos de los legados históricos más sobresalientes de Xochimilco. Estos recorridos fueron precursores del turismo cultural actual, donde ya los itinerarios turísticos se basaban en las zonas más representativas del centro urbano de Xochimilco, aunque dejó de lado a atractivos similares en los demás pueblos de la región.

6. Hiernaux expone el surgimiento de periferias turísticas como resultado de la llegada masiva, durante varias décadas, de personas que buscan espacios de recreación y ocio en las periferias (Hiernaux, 2008). 
El gobierno comenzó, entonces, a organizar eventos con invitados internacionales y a propiciar la inversión privada en los clubes de regata. Todas estas actividades se presentaban como una oportunidad para impulsar el desarrollo económico y la modernización de la zona, para que los pobladores de la región aceptaran compartir su espacio y recursos con los fuereños.

Para 1910, Xochimilco era reconocido como el lugar ideal para la celebración de fiestas (Arqueomex, 2012). Los diarios "El Siglo Diez y Nueve", "El Nacional” y el "Mundo llustrado" difundían sus atractivos para turistas que iban en busca de poblados vernáculos. Por medio de crónicas y fotografías se apreciaban las facilidades que el gobierno ofrecía a los visitantes, como el servicio de vigilancia policial y la instalación de alumbrado (Hernández, 2003). En resumen, el turismo y la vida tranquila de los habitantes de Xochimilco se fundían en narraciones novedosas, románticas y de aventura que atraían fácilmente al turismo. Los diarios funcionaban como una estrategia de difusión mediante la cual el imaginario turístico ${ }^{7}$ era alimentado para visitar Xochimilco y convertirlo en parte de sus vidas.

En esta época Xochimilco era demandado por su belleza paisajística, actividades recreativas, características culturales y el agua de sus manantiales. Sin embargo, la demanda urbana de agua llevó a la construcción de un sistema de captación y distribución del líquido al centro de la ciudad (Hernández, 2003). Para dicha obra fue necesario, también, construir un tranvía que facilitara el traslado de materiales y trabajadores. Este nuevo modo de transporte reforzó la conectividad de la ciudad con el lago y sería aprovechado también por los habitantes de la Ciudad de México, quienes encontraron en él una forma más rápida para desplazarse a los nuevos espacios recreativos.

Nuevos usos de suelo aparecieron en la periferia de la Ciudad de México: clubes de regata, como el inglés y el alemán, y la adecuación de espacios recreativos a orillas de los canales, donde era posible pasar un día de campo ${ }^{8}$. Se puede decir que en esta época empezó el reordenamiento del territorio por el turismo, estimulando cambios urbanos en el centro del poblado dejando relegados a los pueblos cercanos.

Esta modalidad de un turismo pintoresco fue aprovechada por el gobierno, para demostrar que, si bien México se modernizaba, no dejaba de lado sus tradiciones y encanto paisajístico. Sin embargo, desde 1910 el país era sacudido por un movimiento revolucionario que poco a poco fue conquistando el territorio nacional. El movimiento revolucionario llegó a la ciudad por los poblados del sur, lo cual significó un momento de ruptura para la vida y el turismo en Xochimilco. Al igual que en otros lugares del país, se dieron saqueos, incendios y despoblamiento de la región (Hernández, 2003).

7. El imaginario turístico es definido por Daniel Hiernaux como "aquella porción del imaginario social referido al hecho turístico, es decir a las numerosas manifestaciones del proceso societario de viajar, está sujeto a modificaciones provocadas por diversos factores, como las noticias" (Hiernaux, 2002).

8. Las adecuaciones consistían en la instalación de mesas y sillas para los visitantes, pero los espacios eran originalmente dedicados a la agricultura. 


\subsection{Xochimilco y el turismo desarrollista, 1921-1949}

Las estrategias turísticas del porfiriato, así como las ventajas económicas que se generaron, llevaron a los pobladores a aceptar dichas prácticas y, al concluir el movimiento revolucionario en 1921, se agruparon para construir un nuevo embarcadero: "El Salitre", que continúa en servicio. Se reactivó el turismo acompañado de la producción y venta de flores de ornato, la venta de comida en canoas, puestos callejeros, mercados y restaurantes (Hernández, 2003). Casi cien años después, estas actividades continúan siendo de las más rentables, especialmente en el centro histórico y a lo largo de los canales. Con ello se reforzó la territorialización turística, donde la zona centro concentraba la llegada de visitantes.

Se puede afirmar que, si bien la actividad turística surgió a finales del siglo XIX y principios del XX, es a partir del periodo postrevolucionario que aparece el turismo popular que conocemos actualmente, con la particularidad de que la promoción turística ya no sólo la hacía el gobierno, sino que los pobladores participaban y determinaban el uso turístico de los espacios comunitarios. El turismo en Xochimilco se desarrolló rápidamente durante la década de los veinte gracias a la colaboración de los xochimilcas, pero su potencialidad se vería favorecido más adelante.

Durante el gobierno de Lázaro Cárdenas se establecieron estrategias de diversa índole en el lugar. En 1930 se promulgó la Ley Sobre Protección y Conservación de Monumentos y Bellezas Naturales, que se aplicó en la Ciudad de México y en los territorios federales existentes a esa fecha (Cottom, 2011). En el capítulo V de la ley se habla del aspecto típico y pintoresco de las poblaciones, declaratoria que buscaba proteger la imagen original mediante la prohibición de construcciones que alteraran el estilo arquitectónico propio de los pueblos seleccionados (LPCMBN, 1930:35), al conservar el aspecto típico y pintoresco de sus zonas, se buscaba promover el turismo.

Es así como en 1936 Xochimilco fue nombrado Pueblo Típico y Pintoresco, con lo que se buscó preservar las características arquitectónicas y tradiciones, incluyendo las festividades, para fortalecer la identidad cultural. La riqueza socioambiental del lugar fue un modelo de rescate de lo típico, histórico y natural. Como resultado de la Declaratoria, se favorecieron planes de mejoramiento urbano y se facilitaron nuevas formas de acceso a la región (Aréchiga, 2004), con lo cual Xochimilco se consolidó como un destino obligatorio de la Ciudad de México.

Al mismo tiempo, se invirtió en el mejoramiento de la imagen urbana y su comunicación con otras poblaciones cercanas. Si bien estas acciones tuvieron como objetivo principal mejorar la calidad de vida de los habitantes, así como la preservación de sus recursos naturales, también se favoreció al turismo. Los turistas veían a un Xochimilco más urbanizado con las características típicas y pintorescas que se amoldaba al imaginario turístico ensalzado.

Mientras, la Ciudad de México seguía expandiéndose, con lo que aumentaba la ya de por sí creciente demanda de agua, lo que acabó por extinguir el Canal Nacional en 1940 y cancelar la comunicación fluvial prevaleciente entre Xochimilco y el centro de la urbe desde tiempos prehispánicos. Aun así, continuaba como un lugar ideal para el turismo. Entonces, los 
imaginarios turísticos alimentados por las narraciones periodísticas pasaron a la imagen cinematográfica y, en 1943, se rodó en los canales la película "María Candelaria", ícono del cine mexicano en donde se exponía la vida de sus pobladores, la belleza de sus paisajes, costumbres y tradiciones mistificadas.

Después de tres décadas el turismo atravesó una época donde la promoción tripartita en la que convergían pobladores, estrategias gubernamentales y la inversión privada, empujaron a un desarrollo acelerado. Fue en estas décadas cuando el turismo adquirió las características actuales, donde una imagen se amalgamaba con fiestas y elementos que revalorizan identidad y pertenencia a culturas originarias.

En resumen, la política de la época planteaba que el turismo era un motor de progreso $y$, por ende, un camino hacia la modernidad, gracias al cual, Xochimilco pasaría de un pueblo campesino a un pueblo moderno perteneciente al patrimonio intangible.

En esta época Xochimilco presentó también un desarrollo urbano moderado, donde el crecimiento poblacional fue demandando mayores espacios de vivienda, pero, al ser un crecimiento lento (de 22.027 a 33.113 habitantes de 1920 a 1940) y con la simultaneidad del turismo, los xochimilcas se acostumbraron a la presencia de la actividad como parte de su cotidianeidad.

\subsection{De rural a periurbano: $1950-1979$}

El agua del lago de Xochimilco abasteció, desde principios del Siglo XX, a la Ciudad de México. Antes de los años 50 no se preveía un incremento de población grande ni acelerado, por lo cual no se habían tomado medidas para asegurar la preservación del recurso hídrico. Sin embargo, a inicios de la misma década el nivel del agua era tan bajo que varios de sus canales se desecaron. Esto significó una ruptura histórica en Xochimilco. El lago y sus canales comenzaron a ser rellenados con aguas tratadas (ver mapa 2), cuya baja calidad afectó a la biodiversidad endémica, disminuyó la calidad de la agricultura y perdió el encanto cristalino que atraía a los turistas.

Aunado a la decadencia de la agricultura, en la década de los sesenta se construyeron nuevas vialidades para llegar al centro de la Ciudad de México. La construcción y ampliación del Periférico y Prolongación División del Norte formaban parte de las obras para acondicionar la ciudad a los Juegos Olímpicos de México 68, en donde Xochimilco sería escenario de las competencias de remo y canotaje. Estas construcciones ocasionaron el aumento de precio del suelo para su uso habitacional, mientras la población crecía de 70 mil habitantes en 1960 a poco más de 217 mil en 1980 (INEGI, 2017). 
Mapa 2. Plantas de tratamiento de agua que abastecen los canales de Xochimilco

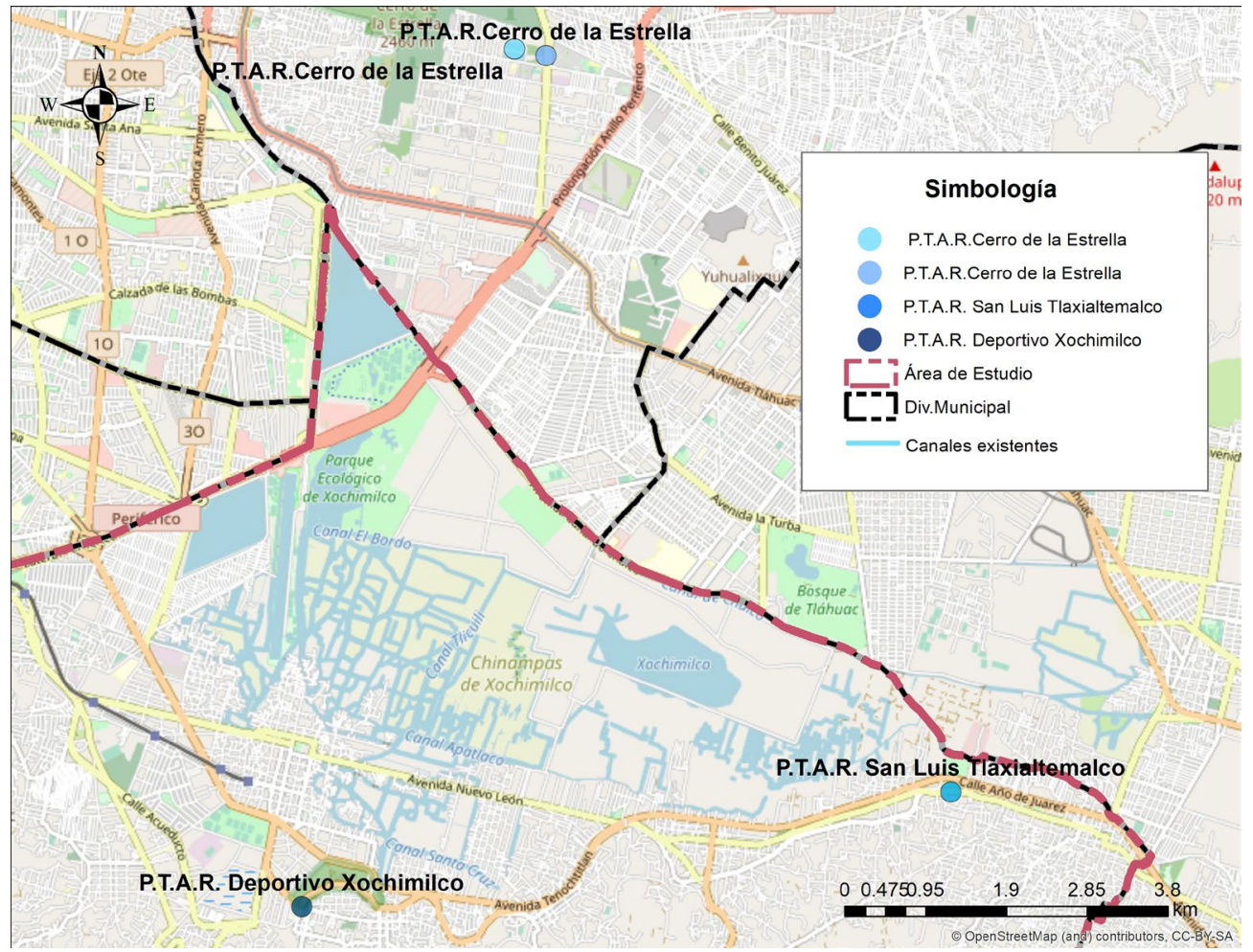

Fuente: Elaboración propia con base en Instituto Nacional de Estadística y Geografía (INEGI).

Este aumento poblacional y los cambios que lo acompañaron persisten en la memoria de los Xochimilcas quienes, a principios de los años 60, podían ver milpas en el centro de la delegación, cuando las casas eran escasas. Se puede considerar este periodo como el de transformación de lo rural a urbano, con la desaparición de las áreas de cultivo en el centro de Xochimilco, la escasez de agua y los canales artificialmente abastecidos, se dio paso a la construcción de casas y pavimentación de vialidades.

De los estragos de una expansión urbana sin control, los más nocivos son los asentamientos irregulares en la zona cerril y a orillas de los pueblos. En estas ocupaciones irregulares se alojan trabajadores llagados desde otros sitios, especialmente de Puebla y el Estado de México, como peones en las zonas de cultivo y mototaxistas entre los pueblos y colonias de la zona. Además, muchos de esos asentamientos irregulares se retroalimentan con la llegada de familiares y conocidos de los ocupantes previos asentados también de forma irregular.

En este periodo la actividad turística de Xochimilco continuaba como una parte natural de la zona, aunque se carecía de todo el auge publicitario que se dio en las décadas anteriores. Sin embargo, la agricultura comenzaba a perder rápidamente fuerza como actividad económica y se veía remplazada por otras. Mientras que, en materia patrimonial, los recursos culturales y naturales de la Alcaldía sufrían un acelerado detrimento ante el crecimiento de la zona urbana.

La suma de estas situaciones llevaría a una crisis ambiental y patrimonial que obligó al gobierno a modificar el enfoque de sus planes, políticas y estrategias en las décadas siguientes. 


\subsection{Urbanización y deterioro ambiental: 1980-1999}

Los efectos antes señalados impulsaron la toma de conciencia sobre los impactos ambientales en buena parte de sus pobladores. La expansión urbana sobre espacios ecológicos obligó a diferentes dependencias a atender el tema urbano ambiental. A principios de los años 80 se adoptaron diversas medidas que debían salvaguardar el patrimonio natural y cultural de la zona.

En 1986 se decretó como Zona de Monumentos Históricos la zona lacustre compartida por las alcaldías de Xochimilco, Tláhuac y Milpa Alta (ver mapa 3). Un año después, en 1987, parte de este polígono fue ratificado por UNESCO, quien declaró Patrimonio Mundial, Cultural y Natural al Sistema de Chinampas de Xochimilco, debido a la conservación de las chinampas como una forma de producción y vivienda en el lago, que incluye elementos como el conocimiento de prácticas agrícolas ancestrales, tecnología en el manejo del agua, aprovechamiento de recursos, organización de trabajo, entre otras (Peralta, 2011b). Terrones (2004) considera que este nombramiento fue un principio para pensar en el futuro de Xochimilco y en la necesidad de proteger el entorno natural, las tradiciones rurales y culturales de los pueblos de la delegación.

Mapa 3. Zona de Monumentos Históricos Xochimilco, Tláhuac y Milpa Alta 1986

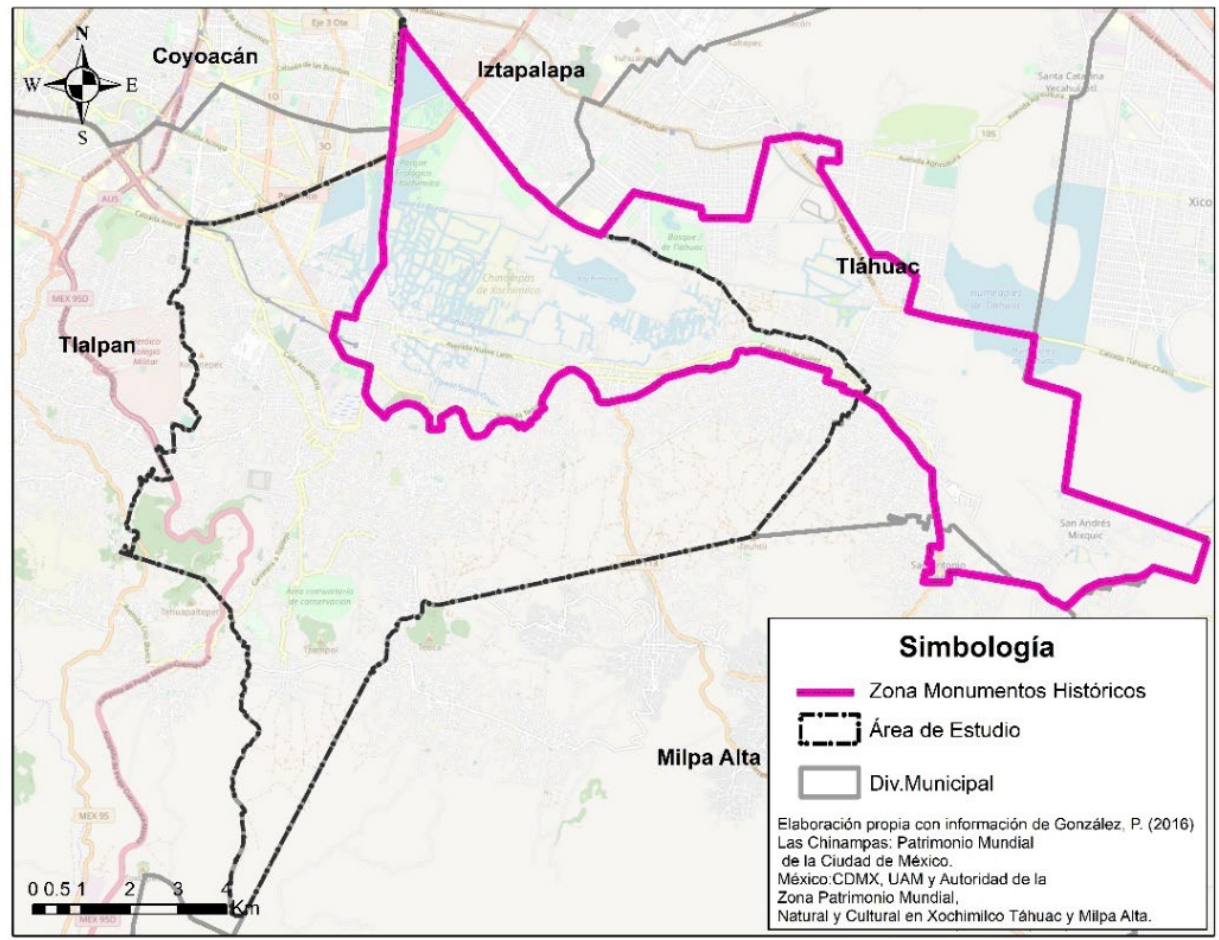

Fuente: Elaboración propia basado en González (2016) Las Chinampas: patrimonio Mundial de la Ciudad de México. México: CDMX, UAM-Xochimilco y Autoridad de la Zona Patrimonio Mundial, Natural y Cultural en Xochimilco, Tláhuac y Milpa Alta.

Esta declaratoria significa el reconocimiento de la comunidad internacional a los valores excepcionales universales del sitio (Peralta, 2011a). Además, se considera como uno 
de los bienes más complejos de América Latina donde un sistema de cultivo artificial generó la consolidación de una población con fuertes valores tradicionales (UNESCO, 2006) lo que une patrimonio tangible e intangible.

Para obtener esa declaratoria, se debía garantizar la puesta en práctica de medidas para conservar y proteger adecuadamente el sistema chinampero. Al dar seguimiento a este compromiso, el gobierno federal identificó tres obstáculos principales: los hundimientos ocasionados por la extracción de agua, la mala calidad de agua usada para rellenar los canales y alimentar las chinampas y la invasión del área urbana en la zona agrícola (Garzón, 2002).

Mapa 4. Zonificación Plan de Rescate Ecológico de Xochimilco 1989

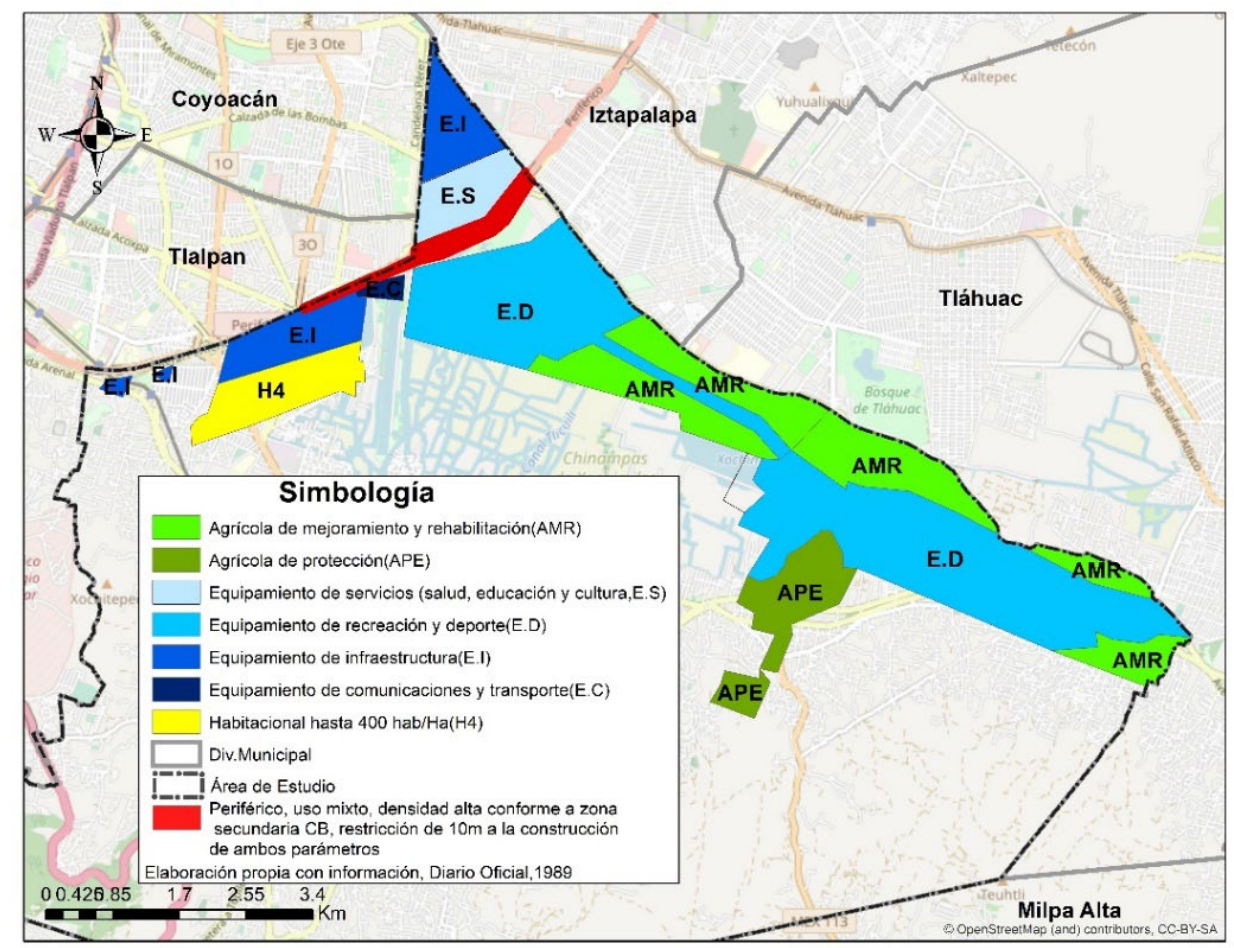

Fuente: Elaboración propia con base en Diario Oficial de la Federación 1989.

Para conservar la categoría de Patrimonio, se instrumentó el Plan Maestro de Rescate Ecológico de Xochimilco en 1989 (ver mapa 4). Se expropiaron 1100 ha. en donde se pretendía construir un lago artificial con fines turísticos y deportivos, un parque de diversiones, un área de clubes y servicios, el incremento de vialidades para facilitar el acceso a la zona de embarcaderos y restaurantes, y un funicular que saldría del embarcadero Fernando Celada a la pista de remo y canotaje en Cuemanco con $21 \mathrm{~km}$ de recorrido donde se podrían apreciar los jardines flotantes y un barco de vapor que permitiría a los visitantes recorrer la zona (Garzón, 2002; Legorreta, 2006). Uno de los objetivos del programa era abrir nuevos espacios recreativos para la Zona Metropolitana de la Ciudad de México. Es decir, ante la crisis ambiental las estrategias ideaban continuar con una territorialidad turística como vía de conservación, enfocándose en 
las virtudes del turismo que, hasta ese momento, habían estimulado más la urbanización de la zona y totalidad del sitio. El apoyo a las actividades agrícolas, consideradas como prioritarias en el decreto de 1987 ya no figuraban, ni siquiera, como discurso.

La propuesta fue rechazada por la comunidad, sobre todo porque incluía la expropiación de tierras con fines lucrativos (Legorreta, 2006). Los ejidatarios recurrieron al amparo con la finalidad de detener el proceso de expropiación, con base en la historia del ejido y su derecho a protegerlo como patrimonio de su pueblo. Un argumento decisivo fue que con la expropiación de tierras se podrían modificar las formas y costumbres de la región (Garzón, 2002). La merma consiguiente del patrimonio intangible de Xochimilco llevaría a la pérdida de la producción chinampera, base del patrimonio cultural característico de la región y por el cual Xochimilco había recibido el nombramiento de unEsCo. Por primera vez, la promoción turística incentivada por el gobierno y los inversores privados había sido rechazada por los pobladores, quienes se negaron a que la reordenación de su territorio se diera por el turismo.

Se formalizó entonces la declaratoria del Área Natural Protegida (ANP) con Carácter de Zona de Conservación Ecológica "Ejidos de Xochimilco y San Gregorio Atlapulco" en 1992, cuyo objetivo era "Conservar los recursos naturales del ecosistema y el paisaje cultural de dicha área por medio del manejo integral de los recursos naturales y la revaloración de las técnicas prehispánicas de producción." (GODF, 2006:21).

Paralelamente, entre 1980 y 2000 se decretaron tres programas de desarrollo urbano para Xochimilco. El primero, en 1980, se centraba en el incremento poblacional y urbano, que ocasionaba considerables problemas viales y desabasto de servicios, pero sin ninguna mención a la conservación ambiental, fuera de la contaminación de los canales, mientras que para el turismo encontraba que los servicios estaban deteriorados. Cierto que se reconocía la pérdida del patrimonio edificado y la necesidad de contar con medidas de conservación (DOF, 1981), aunque no planteaba estrategias. Dicho documento fue redactado más como un diagnóstico que como un instrumento corrector.

En 1987 se elaboró un nuevo Programa, que tenía entre sus objetivos el preservar el patrimonio histórico y cultural del Centro de Xochimilco y regenerar las zonas de chinampas y el sistema de lagunas y canales. En cuanto a las vialidades, se previó la ampliación del Anillo Periférico (DOF, 1987). El nuevo programa buscaba alinearse más con los objetivos de la declaratoria como Zona de Monumentos de 1986 y, por primera vez, proponía la regeneración de las chinampas.

Otra actualización se realizó en 1997, con una referencia especial a los elementos naturales de la delegación, en específico de los relacionados con el agua. Se consideraban de importancia nueve canales y siete lagunas (DOF, 1997), que coinciden con los embarcaderos turísticos más que con las zonas agrícolas, lo que refleja el predominio que se concede al turismo sobre otras formas de generar ingresos en la región.

El mismo documento señala que la oferta de infraestructura vial y de estacionamientos, por tratarse de un lugar de afluencia turística de fin de semana, era insuficiente, por los que 
se sugirió la construcción de 18 estacionamientos en la zona turística ${ }^{9}$ (DOF, 1997), dejando al resto de la zona excluida del servicio.

En síntesis, el turismo continuó presentándose como una alternativa para la conservación de los recursos y el desarrollo local apoyándose en diferentes planes y programas de desarrollo urbano formales. Sin embargo, sería hasta la primera década del siglo XXI cuando se buscaría incidir en el territorio a través de una Secretaría con programas y planes específicamente basados en el turismo.

\subsection{Redefinición turística y la participación social: 2000 - 2016}

Para el año 2000 la Ciudad de México ya era uno de los productos turísticos más atractivos en América, donde los grandes centros de negocios, edificios históricos y actividades nocturnas constituyen los destinos más demandados. Sin embargo, ante la revalorización de la naturaleza y la apertura de nichos ecológicos en el turismo, la ciudad enfrenta ahora el reto de reintegrar los espacios periurbanos con valor ambiental para satisfacer una demanda creciente. Fue así como se planteó formalmente la introducción del Suelo de Conservación al mercado del turismo alternativo, como una estrategia para alcanzar el desarrollo sustentable de la zona.

Hasta entonces, en el decreto del Programa General de Ordenamiento Ecológico del Distrito Federal, se establecieron los límites del Suelo de Conservación y las actividades que pueden realizarse en él, incluidas las turísticas. Con ello se pretendía formalizar un eje rector para todos aquellos programas, planes y medidas que se habían implementado o que se implementarían en el futuro.

A partir de este Programa se revisaron las leyes, planes y programas relacionados con el Suelo de Conservación de la Ciudad de México. La expansión urbana seguía ocupando terrenos de manera regular e irregular, por parte de diferentes sectores de la población.

Si bien durante todo el siglo XX el turismo se fundió con la vida de Xochimilco mediante la diversificación económica, prácticas sociales y diversas transformaciones socio-espaciales, no se generó ningún documento en particular en materia de turismo. Esa función haría pensar en el turismo como algo circunstancial a la conservación ambiental de ese espacio privilegiado.

En efecto, en 2004 la Secretaría de Turismo intervino oficialmente por primera vez en Xochimilco para recuperar la imagen urbana de su centro histórico, se retomaron parte de los decretos de 1936 sobre la imagen típica y pintoresca de la ciudad y se reformuló como uno de los ejes principales para conservar la declaratoria patrimonial de UNESCO.

No obstante, estos objetivos no se han alcanzado por diversos motivos. El primero es el traslape de diferentes dependencias sobre un mismo espacio, en donde confluyen regulaciones que van desde lo internacional a lo local. Se habla de que cada factor (ambiental, urbano, patrimonio, turismo, salud, desarrollo social, producción, entre otros) formula percepciones al mismo tiempo sobre un territorio en el que convergen dos exigencias: la ambiental y la urbana.

9. Esta acción no pudo llevarse a cabo debido a la declaratoria y catalogación patrimonial de la mayor parte de los inmuebles existentes en el centro histórico. 
Algunos espacios se encuentran bajo la jurisprudencia de varios organismos, mientras que otros son dejados de lado, o bien, dentro de los polígonos más intervenidos muchas de las tareas se repiten y en otras aparecen vacíos que afectan la operatividad de sus medidas.

Otros organismos que intervienen también en la actividad turística en el Suelo de Conservación son, a nivel federal: la Comisión Nacional para el Desarrollo de los Pueblos Indígenas (CDI), con el Programa Turismo Alternativo en Zonas Indígenas (PTAZI), y a nivel local: la Secretaría de Desarrollo Rural y Equidad para las Comunidades (SEDEREC), mediante el proyecto de Turismo Alternativo y Patrimonial. En el caso de este último las actividades se llevan a cabo en coordinación con la Secretaría de Turismo (SECTUR) local. No todas las Secretarías coinciden formalmente en un trabajo conjunto entre dependencias turísticas, sociales, ambientales, urbanas y culturales, y aquellas que lo incluyen o bien se quedan en el discurso o la decisión final favorece más al sector turístico que a los pobladores de la comunidad receptora. Los diferentes programas coinciden en que el objetivo principal es mejorar la calidad de vida de los pobladores mediante el turismo para generar empleos y aumentar del ingreso local. También se coincide en la preservación ambiental y cultural de los destinos turísticos, finalmente, se habla de la participación de los prestadores de servicios turísticos y agricultores, en la toma de decisiones correspondientes a este sector.

Las medidas para proteger a Xochimilco seguían implementándose, de modo que entre el 2002 y 2006 se realizaron algunas acciones conjuntas entre UNESCO y la delegación ${ }^{10}$ Xochimilco para la redefinición del polígono y para la creación de un plan de manejo que integrara la participación ciudadana y la colaboración interinstitucional. No obstante, estos avances frenaron por cuestiones de cambios en la administración gubernamental (Zabaleta, 2010). En resumen, existe una declaratoria y un plan de manejo para la zona patrimonial, pero los alcances de las propuestas se han visto limitados.

En 2004 el polígono del ANP fue aceptada como sitio RAMSAR por ser un humedal representativo, además de que se consideró el proceso histórico del territorio, la existencia de chinampas y el albergue de 6 especies endémicas y 20 especies bajo alguna categoría de riesgo; 10 Bajo Protección Especial; 8 amenazadas y dos en peligro de extinción ${ }^{11}$ (Aranda, 2004).

Además, nuevamente se modificaría el Programa de Desarrollo Urbano Delegacional en 2005, en donde se identificaba que el problema enfrentado por Xochimilco era el de una

10. Anteriormente las alcaldías se denominaban como delegaciones, el cambio se dio en la transición gubernamental de 2018, por lo cual en este artículo los términos alcaldía y delegación se refieren a la administración de un espacio territorial específico en la Ciudad de México.

11. En la flora se encuentran: Ninfa (Amenazada), Cedro blanco (Sujeta a protección especial/ introducida), Colorín (Amenazada).

En las especies de Fauna están: Ajolote (Sujeta a protección especial y endémica; Vulnerable), Ajolote tigre de meseta (Sujeta a protección especial); Rana de Tláloc (Peligro de Extinción y endémica); Rana de Moctezuma (Sujeta a protección especial y endémica); Lagartija cornuda de montaña (Amenazada y endémica), Lagartija escamosa de mezquite (Sujeta a protección especial); Culebra listonada (Amenazada); Culebra listonada de montaña (Amenazada y endémica); Tortuga casquito (Sujeta a protección especial); Cincuate (Amenazada y endémica); Cascabel cola negra (Sujeta a protección especial); Pato mexicano (Amenazada y endémica); Garza morena (Sujeta a protección especial); Gavilán pecho rojo (Sujeta a protección especial); Rascón limícola (Sujeta a protección especial) (Aranda, 2004). 
centralidad. Por su ubicación, la zona ocupaba un lugar céntrico desde la época prehispánica e influía en la conformación del ámbito local: la expansión de alcaldías y municipios cercanos como: Tláhuac, Milpa Alta, Chalco y otras localidades lejanas como: Oaxtepec, Amecameca y Cuautla, con lo que se le asignaba una función de paso o transbordo de la movilidad hacia la Ciudad de México y de regreso, agregando a la Alcaldía nuevas funciones como prestadora de servicios regionales (GODF, 2005).

Ahí también se reconocía una subutilización de la infraestructura recreativa, por lo que corrían el riesgo de ser ocupados de forma irregular y además de perder sus valores ambientales, de afectar la cultura, el atractivo turístico y la economía del lugar decaería (GODF, 2005). Para reparar estos riesgos, el programa concede valor primordial al rescate del valor cultural y paisajístico de las áreas con mayor afluencia de turistas, dedicó un apartado a la conservación patrimonial, incorporando sitios patrimoniales a circuitos turísticos, para lo cual se requería la coordinación entre el Instituto Nacional de Antropología e Historia (INAH) y la Dirección de Turismo de Xochimilco (GODF, 2005). Al respecto, quizás una mejor estrategia habría sido recurrir al apoyo financiero de las secretarías estatales y/o federales, así como la asesoría de la UNESCO para una mejor elección del turismo en sitios patrimoniales.

En la actualización de 2012 se consignaron tres subprogramas específicos orientados a la conservación cultural, natural y del desarrollo turístico de la delegación, bajo un enfoque completamente de conservación y/o sustentabilidad ${ }^{12}$ (GODF, 2013).

Durante este periodo, se implementaron programas turísticos específicos. A través de la coordinación entre SECTUR local y SEDEREC se puso en marcha el programa de Turismo Alternativo y Patrimonial 2009-2012 (SECTUR, 2009; SEDEREC, 2013), el cual se dijo que estaba bajo las normas ambientales incluidas en el Programa General de Ordenamiento Ecológico del Distrito Federal (SEDEREC, 2016). Con lo cual enfatizaban el discurso de compromiso hacia un turismo de conservación.

A principios del 2011 se lanzó el programa Barrios Mágicos Turísticos de la Ciudad de México, entre los cuales se encuentra Xochimilco. Esta idea surgió en conjunto de las secretarías de turismo federal y local, el objetivo es detonar la economía de las delegaciones participantes a través del turismo. El programa se basa en el de Pueblos Mágicos debido al "éxito" que ha tenido a nivel federal (Aldaz, 2011). La diferencia en la versión de los barrios mágicos es que su imagen e infraestructura no se tiene que unificar para conservar el aspecto "típico" de las poblaciones, como sucedió en 1936, pero sí se trabaja desde esa fecha en la mejora de la imagen urbana y vialidad, además de sacar los negocios no relacionados con el turismo de los polígonos seleccionados.

Como se había comentado, la experiencia de los vecinos de Xochimilco en el turismo inició a principios del siglo XX, y en 1989 se dio la primera oposición a que el turismo fuera más

12. "El Programa de Salvaguarda del Patrimonio Histórico y Cultural”, cuyo objetivo es conservar el acervo cultural e histórico, con especial énfasis en las chinampas y en el patrimonio intangible. Los "Programas Parciales de Desarrollo Urbano en el Suelo de Conservación", enfocados en atender las necesidades de los poblados originarios y de la formación de asentamientos humanos irregulares, y el "Programa de Desarrollo Integral de Turismo", que incluía la creación de rutas turísticas, una mejor promoción del sitio y la inversión pública en infraestructura. 
importante que la agricultura. Esta situación se repitió en el 2016, cuando FONATUR (Fondo Nacional de Fomento al Turismo) intentó implementar el Programa de Desarrollo Turístico Alternativo y Sustentable de Pueblos Originarios de la Ciudad de México en; Xochimilco, Tlalpan y Magdalena Contreras.

Este programa busca fortalecer y posicionar en forma ordenada la actividad turística a nivel regional, aprovechando los atractivos turísticos naturales y culturales, además de lograr un mejoramiento de la imagen urbana, trabajar en la calidad de los servicios turísticos, brindar apoyos estratégicos, investigaciones y proyectos, trabajar en las estrategias de mercado y campañas de promoción turística, entre otros. En el caso de Xochimilco éstas se integran por los canales, los pueblos de montaña, las tradiciones y el bagaje cultural (SECTUR, FONATUR, CDMX, \& SEDEREC, 2016).

El rechazo a este programa se basa en que está redefiniendo el uso de espacios y recursos (naturales y culturales) como parte de una estrategia impulsada por el gobierno e inversores privados, dejando de lado a los pobladores, prestadores de servicios turísticos y agricultores, quienes han desarrollado una identidad con el espacio que incluye usos tradicionales.

El turismo periférico de Xochimilco, tras una larga trayectoria, actualmente se encuentra en un momento de crisis donde los programas no logran la conservación ambiental, además de que los pobladores, si bien continúan con la actividad turística, no confían en que sea el gobierno quien regule la actividad y determine los usos de suelo, primordialmente agrícolas, a favor del turismo. Situaciones que han tratado de resolverse en los últimos años sin grandes avances.

Finalmente, se retomó a nivel internacional la importancia de la agricultura en chinampa en julio de 2017, cuando la Organización de las Naciones Unidas para la Alimentación y la Agricultura (FAO), felicitó al Gobierno de la Ciudad de México por el reconocimiento oficial del sistema agrícola chinampero como Sistema Importante del Patrimonio Agrícola Mundial (SIPAM).

\section{EL TURISMO EN XOCHIMILCO VISTO POR SUS POBLADORES}

Si bien hasta el momento hemos presentado la dinámica entre el turismo y la expansión urbana desde lo gubernamental, es importante conocer las percepciones de quienes se relacionan día a día con este espacio, tanto como lugar de trabajo como vivienda. Por tanto, se realizó un trabajo de campo dividido en dos etapas: en la primera se entrevistaron productores de la zona chinampera de Xochimilco como parte del proyecto de Valoración Económicoambiental del Suelo de Conservación del Distrito Federal (CONACYT-CB-179301). De esta etapa se entrevistó un total de 13 agricultores de San Gregorio, el mercado de flores y Tulyehualco.

En la segunda etapa se entrevistaron 11 prestadores de servicios turísticos contactados directamente en sus sitios de trabajo, a los representantes de los pueblos y barrios de Xochimilco, contactados en las reuniones realizadas para manifestar su oposición a los proyectos turísticos de Fonatur. Finalmente, también se entrevistaron a 19 habitantes de la delegación, contactados a través de la técnica bola de nieve. Se seleccionaron aquellos habitantes que 
llevaran más de 30 años viviendo en la delegación y que, de preferencia, fueran hijos de habitantes originarios.

Los resultados de dichas entrevistas pueden dividirse en tres segmentos: la percepción en general del turismo, la rentabilidad económica de esta actividad y la relación entre el turismo y el desarrollo urbano.

Sobre la percepción de la actividad, los pobladores ven al turismo como algo normal que se ha fundido en la cotidianeidad. Resalta que los agricultores ven al turismo como una actividad bondadosa que ellos mismos tratan de promover en las zonas de cultivo, ya que consideran que esto les asegurará no sólo una mayor ganancia económica, sino también una mayor inversión en los canales y chinampas agrícolas. Mientras que los representantes de pueblos y barrios tienden a rechazar al turismo impuesto por las secretarias o inversores particulares ya que, por experiencias previas, temen la expropiación de tierras y verse sólo contratados como trabajadores.

El fenómeno que se da en torno a la rentabilidad es muy complejo. Encontramos que no es la principal actividad económica, ya que la afluencia se da en fines de semana, días festivos y vacaciones. Fuera de esos días aquellos que son trabajadores de embarcaderos, restaurantes y demás servicios turísticos, se dedican a otras actividades entre semana. Cabe señalar que muchos son profesionistas: veterinarios, enfermeros y profesores de educación básica. El principal motivo por el cual se dedican a la actividad turística, además de los beneficios económicos, es la identidad que han forjado, ya que son oficios heredados por generaciones.

Finalmente, sobre el papel del turismo en la urbanización de Xochimilco, nos sorprendió en el sentido de que, a pesar de las pruebas documentales referidas en la investigación, los habitantes no han percibido transformación alguna, aunque sí reconocen llevar a cabo modificaciones en el uso de los espacios cuando hay mayor afluencia turística: convierten los patios de las casas en estacionamientos públicos y las cocinas familiares se transforman en restaurantes.

En síntesis, la implementación de programas turísticos en el Suelo de Conservación ha tenido en la práctica dos resultados. El primero se refiere a las comunidades que han aprendido a trabajar conjuntamente para preservar el espacio ecológico, sus costumbres y tradiciones y transmitirlo a los más jóvenes y a los visitantes nacionales y extranjeros. En segundo lugar, aún se presentan problemas ambientales, como son los cambios de uso del suelo para actividades recreativas no regularizadas (Pérez, 2011), culturales en términos del patrimonio construido, y socioeconómicos por la segregación.

\section{PARA LA REFLEXIÓN: EL FUTURO DEL TURISMO PERIURBANO DE XOCHIMILCO}

Para entender los efectos de la expansión urbana en Xochimilco, distintos programas de gobierno, equipos académicos y organizaciones civiles han realizado estudios diversos. Sin embargo, la mayor parte de trabajo de los estudios de la zona lacustre, y los mejores resultados se tienen en Patrimonio de la Humanidad, ANP y Sitio Ramsar. También hay avances menores en el manejo de la expansión urbana, el cambio de uso de suelo, la conservación 
ambiental, la protección de la fauna endémica y la producción agrícola, aunque poco se habla del papel del turismo como agente urbanizador.

Se puede concluir que el turismo periurbano ha sido una constante en la zona que, si bien ha evolucionado en función de las necesidades propias del lugar, también lo fue modificando. El turismo periurbano inició con un enfoque de desarrollo que buscaba la modernización de Xochimilco y un desarrollo económico local que mejorara la calidad de vida de los pobladores mediante el turismo. Además, la participación de los actores (gobierno, inversores y pobladores) funcionaba en sentido vertical y unilateral, donde el gobierno tomaba las principales decisiones y los habitantes las aceptaban.

Posteriormente, con la expansión urbana de la Ciudad de México llegaba la modernidad y urbanización a Xochimilco acompañada de una fuerte inversión estatal para la construcción de vialidades, que facilitaron, a su vez, la expansión urbana y demográfica, la cual fue más allá de lo que se esperaba, acarreando un detrimento ambiental y patrimonial alarmante que llevó a plantearse la necesidad de implementar estrategias de rescate y conservación. Sin embargo, en estas estrategias el turismo se mantuvo presente bajo un discurso de conservación. Hubo varios intentos para incluir inversores privados para la construcción de una imagen turística que, finalmente, iba a generar cambios de usos de suelo, reflejados en la construcción de centros turísticos de gran tamaño, funcionamiento de tour operadoras y servicios complementarios.

Cuando se realizó la transición formal de la agricultura tradicional al turismo sustentable, por lo menos en el discurso, el desarrollo económico y la calidad de vida de los pobladores se planteaban como prioridad y como una vía para fortalecer la identidad con el lugar y, de este modo, generar una conciencia de conservación ambiental y patrimonial. A pesar de ello, esos programas continúan sin acuñar una meta clara, y es que las "nuevas" estrategias siguen los patrones del enfoque de un turismo de desarrollo. Por ejemplo, en 1936 se decretaron los Pueblos Típicos y Pintorescos como una forma de generar atracción turística y, a partir del 2011, Xochimilco se integró al Programa de Barrios Mágicos que sigue la misma dinámica de preservar una imagen, pero ahora con el objetivo de generar conciencia sobre la importancia de preservar el patrimonio.

Con ello, el turismo ha pasado de una perspectiva desarrollo a una de sustentabilidad siguiendo una línea de estrategias gubernamentales replicadas en el territorio a lo largo de estos periodos. Esto significa que el turismo de conservación no ha madurado plenamente, de forma que subsisten rasgos del turismo de desarrollo, especialmente en aquellas estrategias implementadas en los pueblos originarios de la delegación que se encuentran fuera de la zona turística tradicional.

Sin embargo, la implementación de un turismo de conservación intenta responder a un proceso de conservación ambiental que convive, desde hace 50 años, con un intenso proceso de urbanización y que difícilmente podrá detenerse, ya que la ciudad continúa creciendo y demandando espacios de vivienda, recreación, servicios, infraestructura, entre otros. en este contexto, una actividad turística que más allá de buscar el mantener intactos los recursos naturales y los espacios protegidos por las diferentes declaratorias, se encuentra inmersa en una dinámica de oferta para el turismo masivo. 
En síntesis, el desarrollo de las periferias turísticas es un fenómeno heterogéneo que no se da de igual forma en todos los casos. El turismo en este caso se ha percibido, desde hace más de un siglo, como un agente que conduciría al desarrollo económico y social de las comunidades anfitrionas, al mismo tiempo que genera conciencia y medidas para la protección de sus características naturales y culturales. En la práctica, estas mejoras se llevan a cabo en los espacios que son visitados por los turistas.

En cuanto a la operatividad turística, se considera que las acciones gubernamentales deben cambiar el enfoque up-down e integrar a los pobladores, campesinos y prestadores de servicios turísticos, como actores participativos en el desarrollo de actividades turísticas dentro de la alcaldía. Por otro lado, es necesario replantear el enfoque para ir más allá del desarrollo socioeconómico y/o la conservación ambiental, pensando en un destino que se encuentra bajo una dinámica más compleja en la que el desarrollo urbano sigue demandando espacios para la vivienda y la recreación al mismo tiempo que la crisis ambiental busca conservar la mayor cantidad de Suelo de Conservación.

Es necesario ir más allá de la implementación de un turismo ecológico o agroturismo en el caso de las zonas productoras, y pensar en Xochimilco como la periferia de una metrópolis que es multidestino. Desde el enfoque de lo urbano, se recomienda ver a estas zonas no sólo como la frontera entre lo urbano y lo rural, sino como un espacio donde las actividades predominantes y compatibles (turismo y agricultura) deben participar activamente en la planeación de los espacios de manera integrada para evitar que sea el turismo quien dirija esa territorialización.

\section{Agradecimientos}

Al Consejo Nacional de Ciencia y Tecnología (CONACYT) por la beca para la realización de los estudios de Doctorado, de los cuales se desprende este artículo.

Al Consejo Nacional de Ciencia y Tecnología (CONACYT) por el apoyo recibido, a través del Proyecto 179301 “Valoración Económico-Ambiental del Suelo de Conservación del Distrito Federal", para la realización de la investigación que dio pie a este artículo.

A la Universidad Autónoma Metropolitana Unidad Azcapotzalco, por recibir la propuesta y facilitar su desarrollo en el doctorado de Diseño y Estudios Urbanos. Al Instituto de Geografía y al Programa Universitario de Estudios sobre la Ciudad, ambos pertenecientes a la Universidad Nacional Autónoma de México por apoyar en el trabajo de campo y culminación de la investigación. 


\section{REFERENCIAS BIBLIOGRÁFICAS}

Aldaz, P. (2011). Alistan los primeros tres barrios mágicos . El Universal. Retrieved from http:// archivo.eluniversal.com.mx/ciudad/106060.html

Allen, A. (2003). Environmental planning and managment of the peri-urban interface: perspectives on an emerging field. Environment \& Urbanization, 15(1), 135-148.

Aranda, M. (2004). Ficha Informativa de los Humedales Ramsar . Retrieved from http://www. conanp.gob.mx/conanp/dominios/ramsar/docs/sitios/FIR_RAMSAR/Distrito_Federal/ Xochimilco/Sistema\%20Lacustre\%20Ejidos\%20de\%20Xochimilco\%20y\%20San\%20 Gregorio\%20Atlapulco.pdf

Aréchiga, E. (2004). De la exuberancia al agotamiento. Xochimilco y el agua, 1882-2004. In M. Terrones (Ed.), A la orilla del agua. Política, urbanización y medio ambiente. Historia de Xochimilco en el Siglo XX (1st ed., pp. 97-152). México D. F: Gobierno del Distrito Federal, Delgación Xochimilco, Instituto de Investigaciones Dr. José María Luis Mora.

Arias, S., \& Ávila, D. (2013). Criterios urbanos sustentables en la periferia urbana de Guadalajara (México). Territorios, (28), 41-77.

Arqueomex. (2012). Xochimilco en el Siglo XX. Xochimilco Patrimonio de la Humanidad (43). México: Revista de Arqueología Mexicana.

Chaperon, S., \& Bramwell, B. (2013). Dependency and agengy in peripheral tourism development. Annals of Tourism Research , 40, 132-154.

Cottom, B. (2011). Patrimonio Cultural Nacional: el marco jurídico y conceptual. Retrieved from http://www.juridicas.unam.mx/publica/librev/rev/derycul/cont/4/ens/ens11.pdf

da Silva, C., \& Correia. (2015). INTRODUÇÃO AO TURISMO. Brasil: Universidade da Medeira. Retrieved from http://www3.uma.pt/fcf/IMG/pdf/RoteiroTuristicoPortoMoniz Final.pdf

Diniz, K., \& Moquete, S. (2011). El turismo en la Dinámica Territorial. ¿Lógica global, desarrollo local? Estudios y Perspectivas En Turismo, 20(2), 441-461.

DOF. (1981). ACUERDO No. 104 por el cual se aprueba el Plan Parcial para la Delegación Xochimilco, D. F. . México: DOF. Retrieved from http://www.dof.gob.mx/nota detalle. php?codigo $=4607083 \&$ fecha $=26 / 01 / 1981$

DOF. (1987). Programa Parcial de Desarrollo Urbano del Distrito Federal de la Delegación Xochimilco 1987. México: DOF.

DOF. (1997). Programa Delegacional de Desarrollo Urbano de Xochimilco 1997. (D. Federal, Ed.). México: Diario Oficial de la Federación 16/06/97.

Garzón, L. (2002). Xochimilco Hoy. México: Gobierno del Distrito Federal, Delegación Xochimilco, Instituto de Investigaciones Dr. José María Luis Mora.

GODF. (2005). Decreto que contiene el Programa Delegacional de Desarrollo Urbano para la Delegación del Distrito Federal en Xochimilco . (D. Federal, Ed.). México: Gaceta Oficial del Distrito Federal.

GODF. (2006). Programa de Manejo del Área Natural Protegida con Carácter de Zona de Conservación Ecológica "Ejidos de Xochimilco y San Gregorio Atlapulco." (D. Federal, Ed.). México: Gaceta Oficial del Distrito Federal .

GODF. (2013). Decreto que contiene el Programa Delegacional de Desarrollo Urbano para la Delegación Xochimilco del Distrito Federal 2012-2015. México: Gobierno del Distrito Federal. 
Gómez, M. (2005). Weather, climate and tourism. A geographical perspective. Annals of Tourism Research, 32(3), 571-591.

Hernández, H. (2003). Xochimilco Ayer III. México: Gobierno del Distrito Federal, Delegación Xochimilco, Instituto de Investigaciones Dr. José María Luis Mora .

Hiernaux, D. (1989). La dimensión territorial de las actividades turísticas. In D. Hiernaux (Ed.), Teoría y praxis del espaco turístico (1st ed., pp. 53-73). México: UAM-Xochimilco.

Hiernaux, D. (2002). Turismo e imaginarios. Cuaderno de Ciencias Sociales, (123), 7-35.

Hiernaux, D. (2008). El giro cultural y las nuevas interpretaciones geográficas del turismo. GEOUSP Espaco e Tempo, (23), 177-187.

Hohl, A. E., \& Tisdell, C. A. (1995). Peripheral tourism. Development and management. Annals of Tourism Research, 22(3), 517-534. https://doi.org/10.1016/0160-7383(95)00005-Q

INEGI. (2017). Censos y Conteos de Población y Vivienda. Serie Histórica Censal. México: Instituto Nacional de Estadística y Geografía Consultado en http://www.inegi.org.mx/ est/contenidos/Proyectos/ccpv/

Legorreta, J. (2006). El agua y la Ciudad de México: de Tenochtitlán a la megalópolis del siglo XXI . México: UAM Azcapotzalco.

LGEEPA. (1988). Ley General del Equilibrio Ecológico y la Protección al Ambiente. México .

LPCMBN. (1930). Ley Sobre Protección y Conservación de Monumentos y Bellezas Naturales. Retrieved from http://iisoc.sociales.unam.mx:9090/isp/leves/despliegaRecursivo.jsp

Nash, R., \& Martin, A. (2003). Tourism in peripheral areas?the challenges for northeast Scotland. International Journal of Tourism Research, 5(3), 161-181. https://doi.org/10.1002/ itr.426

PAOT. (2007). El Suelo de Conservación del Distrito Federal. México: Procuraduría Ambiental y de Ordenamiento Territorial del Distrito Federal. Retrieved from http://www.paot.org. $\mathrm{mx} /$ centro/programas/suelo-corena.pdf

Peralta, A. (2011a). Patrimonio arquitectónico . In Xochimilco y su patrimonio cultural (pp. 107176). México: Instituto Nacional de Antropología e Historia .

Peralta, A. (2011b). Patrimonio Natural . In Xochimilco y su patrimonio cultural (pp. 31-56). México: Instituto Nacional de Antropología e Historia .

Pérez, E. (2011). Desarrollo Urbano Sustentable. In E. Pérez \& M. de la L. Valderrábano (Eds.), Medio Ambiente, sociedad y políticas ambientales en el México Contemporáneo . México: Porrúa, IPN, Universidad Autónoma de Guerrero.

Pérez, A. (2018) El turismo periférico en el Suelo de Conservación de Xochimilco. Del turismo de desarrollo al turismo de conservación. Universidad Autónoma Metropolitana - Azcapotzalco.

SAGARPA. (2018). Las chinampas, un antiguo y eficiente sistema de producción de alimentos. México: Secretaría de Agricultura, Ganadería, Desarrollo Rural, Pesca y Alimentación. Retrieved October 17, 2018, from https://www.gob.mx/sagarpa/articulos/ la-agricultura-en-chinampas.

SECTUR. (2009). Tercer informe de labores. México, D.F.: Secretaría de Turismo.

SECTUR, FONATUR, CDMX, \& SEDEREC. (2016). Programa de Desarrollo Turístico Alternativo y Sustentable Pueblos Originarios de la Ciudad de México en: Xochimilco, Tlalpan y Magdalena Contreras (Versión Reservada). México: Secretaría de Turismo, Fondo 
Nacional de Fomento al Turismo, Gobierno de la Ciudad de México y Secretaría de Desarrollo Rural y Equidad para las Comunidades.

SEDEREC. (2013). PROGRAMA DE TURISMO ALTERNATIVO Y PATRIMONIAL DE LA CIUDAD DE MÉXICO CORRESPONDIENTE AL EJERCICIO 2012. . México: SEDEREC. Retrieved from http://www.sederec.df.gob.mx/sites/default/files/padron turismo.pdf

SEDEREC. (2016). Programa turismo alternativo y patrimonial de la Ciudad de México. Retrieved from http://www.sederec.cdmx.gob.mx/programas/programa/ programa-turismo-alternativo-y-patrimonial-de-la-ciudad-de-mexico

Terrones, M. (2004). Prefacio. In M. Terrones (Ed.), A la orilla del agua. Política, urbanización y medio ambiente. Historia de Xochimilco en el Siglo XX (1st ed., pp. 11-17). México: Gobierno del Distrito Federal, Delegación Xochimilco, Instituto de Investigaciones Dr. José María Luis Mora.

UNESCO. (2006). Xochimilco, Tláhuac, Milpa Alta. "Resumen del plan integral y estructura de gestión del polígono de Xochimilco, Tláhuac y Milpa Alta, inscrito en la lista del patrimonio mundial de la UNESCO. México: UNESCO-México, Gobierno del Distrito Federal.

Yang, Z., Cai, J., \& Sliuzas, R. (2010). Agro-tourism enterprises as a form of multi-functional urban agriculture for peri-urban development in China. Habitat International, (34), 374-385.

Zabaleta, D. (2010). El Proyecto Unesco-Xochimilco (PUX), en la Ciudad de México. Alcances y límites de la gobernanza democrática en iniciativas propuestas por gobiernos locales con institucionalidad débil. (I. de recherche et débat sur La \& Gouvernance., Eds.). Retrieved from http://www.institut-gouvernance.org/fr/experienca/fiche-experienca-27.html

Zasada, I. (2011). Multifunctional peri-urban agriculture-A review of societal demands and the provision of goods and services by farming. Land Use Policy, (28), 639-648. 